\title{
Pandangan Alkitab Tentang Suap dan Pungli
}

\author{
Dixon Nixon Siathen \\ Sekolah Tinggi Teologi Baptis Indonesia Semarang \\ kharissiathen@gmail.com
}

\begin{abstract}
ABSTRAK
Masalah uang suap dan pungli telah mewabah hebat, hal itu yang mesti dihadapi oleh rakyat Indonesia, termasuk umat Kristen jika berurusan dengan aparat birokrasi pemerintah. Mereka sering tidak tahu apa yang harus dilakukan. Kalau memberi uang pelicin seringkali rasa berdosa datang mengusik dalam hati. Hal tersebut terjadi karena kurang memahami bagaimana pandangan Alkitab mengenai suap dan pungli. Apakah memberi suap itu berdosa? Tujuan dari penelitian ini adalah mengetahui pandangan Alkitab tentang uang pelicin yang meliputi tindakan suap dan pungli. Kalau suap, firman Tuhan jelas menegaskan bahwa hal itu merupakan perbuatan berdosa. Tuhan menegor dan mengecam keras pelaku pemerasan atau penerima pungli. Pemberi pungli adalah orang lemah korban pemerasan, yang dilakukan oleh orang yang memiliki kekuasaan. Allah melarang adanya pemerasan kepada sesama manusia (Im.19:13). Allah tidak menyukai dan mengecam orang yang memeras orang lain. Ancangan penelitian ini adalah penelitian kualitatif bukan eksperimental karena tujuannya bukan mencari angka-angka dan eksperimen atau percobaan, tetapi menggunakan kajian deskriptif. Metode penulisan ini bersifat analisis dan deskriptif.
\end{abstract}

Kata kunci: pungli, suap, pandangan Alkitab

\section{PENDAHULUAN}

Uang pelicin yang meliputi suap dan pungli sudah bukan hal baru di Indonesia. Latar belakang semaraknya uang pelicin yang juga menyangkut suap dan pungutan liar (untuk selanjutnya ditulis pungli) di negara Republik Indonesia sekarang ini, tidak terlepas dari pengaruh feodalisme masa lalu. Raja-raja masa lalu menuntut upeti dari bawahan, dan bawahan juga sama sampai tingkat bawahan terendah. Demikian juga upeti wajib diberi bila masyarakat ingin bertemu pejabat. Sebagai pengaruh feodalisme masa, maka muncul kebiasaan memberi uang pelicin yang meliputi suap dan pungli kepada aparat birokrasi pemerintah, yang berkelanjutan sampai sekarang. Akibatnya anggota masyarakat sangat dirugikan, dan timbul suatu pemerasan terhadap dunia perdagangan, serta kolusi dengan kekuasaan demi keuntungan yang besar.
Masalah uang pelican dalam bentuk suap dan pungli sudah menjadi fenomena hari lepas hari di berbagai kantor pemerintah, dan di lapangan yang melayani masyarakat. Tragisnya, perbuatan itu telah menjadi "rahasia umum" dan oknum pelakunya tidak lagi kenal malu. Kalau di negara lain korupsi itu dipandang sebagai perbuatan yang tercela, di negara Indonesia justru dikejar untuk dinikmatinya. Karena itu tidak mengherankan kalau ada pernyataan, bahwa "Korupsi di Indonesia telah terkenal di mana-mana", demikian yang pernah diucapkan oleh mantan Presiden Bank Dunia Mac Namara.

Masalah uang pelicin yang termasuk suap, dan pungli tersebut telah mewabah hebat, hal itu yang mesti dihadapi oleh rakyat Indonesia, termasuk umat Kristen jika berurusan dengan aparat birokrasi pemerintah. Mereka sering tidak tahu apa yang harus dilakukan. Kalau memberi uang pelicin, kerapkali rasa berdosa datang mengusik dalam hatinya, sebab kurang memahami apa pandangan Kristen soal uang 
pelicin itu. Apakah memberi uang pelicin itu berdosa? Kalau suap, firman Tuhan jelas menegaskan bahwa itu sebagai perbuatan berdosa, tapi yang berdosa itu pemberi suap atau penerimanya? Untuk menjawab pertanyaan tersebut diperlukan pengajaran soal uang pelicin, suap, dan pungli.

Berdasarkan latar belakang permasalahan di atas maka tujuan dari penelitian ini adalah mengetahui pandangan Alkitab tentang uang pelicin yang meliputi tindakan suap dan pungli.

\section{METODE PENELITIAN}

Ancangan penelitian adalah penelitian kualitatif, bukan eksperimental karena tujuannya bukan mencari angka-angka dan eksperimen atau percobaan, tetapi menggunakan kajian deskriptif. Metode penulisan ini bersifat analisis dan deskriptif. Analisis yang dimaksud adalah data berupa pandangan Alkitab tentang masalah suap dan pungli hingga membentuk pemahaman atau pengertian yang terbatas.

\section{PEMBAHASAN \\ Pengertian Suap}

Istilah suap dalam bahasa Inggris adalah bribe, yang artinya: uang sogok, suap, uang semir. Dari kata kerja transitip (transitive verb) adalah: menyogok atau menyuap. Kata bribery artinya penyuapan, penyogokan, suapan, dan sogok. Sedang menurut Kamus Umum Bahasa Indonesia yang disusun oleh WJS. Poerwadarminto memiliki pengertian hanya sebagai uang sogok. Jadi nama lain untuk uang suap adalah uang sogok.

Istilah suap dalam bahasa Ibrani dipakai kata kopher, yang artinya: bribe (suap), ransom (uang tebusan), satisfaction (pelunasan), yang digunakan pada kitab I Samuel 12:3; Amos 5:12. Juga dipakai istilah shakhad, artinya: bribe, gift (hadiah), present (hadiah, pemberian), reward (ganjaran, upah, pahala, hadiah, membalas), yang digunakan pada I Samuel 8:3; Ayub.15:34; Mazmur 26:10; dan Yesaya 33:15.

Verkuyl dalam buku Etika Kristen: Sosial Ekonomi, memberikan pengertian suap, yaitu: Suatu ikhtiar untuk membujuk orang agar menyalahgunakan kedudukan dan kekuasaannya dengan maksud mencari untung bagi dirinya (pemberi suap) dan juga memberikan keuntungan bagi pejabat tersebut. Jadi tujuan suap adalah untuk memperlancar suatu urusan, dengan membujuk aparat yang memiliki wewenang untuk kepentingan pemberi suap, dengan memberikan uang atau sesuatu barang sebagai imbalan.

\section{Pengertian Pungli}

Istilah pungli singkatan dari pungutan liar. Menurut Kamus Umum Bahasa Indonesia, istilah pungutan dari kata pungut atau memungut yang artinya: menarik bea, pajak, uang iuran, derma, dan sebagainya. Pungutan adalah hasil dari yang dipungut. Sedang liar artinya: tidak jinak, ganas, tidak menurut aturan, atau tidak teratur. Jadi Pungli berarti menarik uang atau bea dengan tidak menurut peraturan atau undang-undang yang berlaku.

Istilah pungli kebetulan terdapat juga dalam Kamus Bahasa Mandarin. Puung artinya persembahan, dan li artinya keuntungan. Berarti puungli dapat diartikan: petugas atau pejabat yang berkuasa meminta persembahan demi keuntungannya dari masyarakat atau orang lain.

Pungli dalam praktiknya, yaitu aparat atau petugas meminta uang pungli di luar peraturan yang berlaku kepada masyarakat yang berurusan dengannya, yang jika tidak diberi akan menghadapi berbagai kesulitan, sejauh yang bisa dilakukan oleh oknum aparat tersebut.

Soedjono D. seorang pakar hukum memberikan batasan atau definisi pungli sebagai berikut: Pungli adalah pungutan yang dilakukan oleh dan untuk kepentingan pribadi oknum petugas dan atau bertujuan kepentingan tertentu individu masyarakat, terhadap uang negara dan atau anggota masyarakat yang dipungut secara tidak sah (tidak memenuhi persyaratan formil maupun materiil) dan atau melawan hukum (tindak pidana). Istilah lain yang dipergunakan di dalam dan oleh masyarakat yang terkandung di dalam arti pungli sebagaimana terurai pada batasan di atas, adalah uang pelicin, uang sogok, uang semir, salam tempel, uang administrasi, uang ikhlas, $3 \mathrm{~S}$ ( senang sama senang).

\section{Pandangan Alkitab Tentang Suap}

Permasalahan suap yang terjadi pada masa Perjanjian Lama, pada kitab Ulangan 16:9 
tertulis demikian: Janganlah memutarbalikan keadilan, janganlah memandang bulu dan janganlah menerima suap, sebab suap membuat buta mata orangorang bijaksana dan memutarbalikan perkataan orang-orang benar. Hal itu memperlihatkan adanya kebiasaan para hakim yang menerima suap pada zamannya. Kata memutarbalikkan, yang arti harfiahnya adalah membuat miring, condong, atau serong. Hakim yang berbuat demikian memang tidak menyangkali hak orang benar secara terang-terangan, tapi meniadakannya secara halus. Suap dapat membuat orang bijaksana menjadi tidak dapat lagi melihat mana yang benar dan mana yang salah, kemudian mengambil sikap perilaku buruk dan tidak adil serta jahat terhadap orang benar.

Cairns menyebutkan bahwa perkataan, "Janganlah menerima suap, sebab ..." adalah kalimat yang dipakai secara luas sejak zaman kuno yang tercermin juga dalam literatur "kebijaksanaan" (band Ams.17:23), di mana penerimaan suap menjadi gejala kronis di Israel (Yes. 1: 23; 5:23; Mi.3:11: Yeh.22:12). Dan ternyata perkataan tersebut masih sangat relevan sampai sekarang.

Praktik suap tidak hanya terjadi di kalangan aparat penguasa, tapi juga menjalar pada kaum rohaniwan, yang dikisahkan dalam kitab Mikha 3:11 sebagai berikut: Para kepalanya memutuskan hukum karena suap dan para imamnya memberi pengajaran karena bayaran, para nabinya menenung karena uang, padahal mereka bersandar kepada Tuhan dan berkata: "Bukankah Tuhan ada di tengahtengah kita!".

Firman itu mengungkapkan bahwa para pimpinan, imam, dan nabi hanya mau menjalankan tugasnya setelah diberi uang suap atau uang bayaran sebagai imbalan, sehingga orang miskin menjadi korban, dan orang-orang kaya dapat meneruskan praktik menyuap (band. Yes.1:23; Yer.5:28).

Sebenarnya para imam wajib memberi pengajaran agama dengan gratis, karena ia sudah dijamin dari penghasilan bait Allah. Namun demi uang ia bersedia memberikan petunjuk-petunjuk lain yang tidak seharusnya asal sesuai bagi yang membutuhkan atau yang membayar, demikian juga para nabinya. Meskipun mereka merasa berdosa, namun meyakini bahwa Tuhan ada di tengah mereka. Hal itu menggambarkan hati nurani para penerima suap yang sudah bebal, dan hidupnya hanya untuk uang belaka.

Nabi Yesaya menceritakan mengenai perkara suap sebagai berikut: Para pemimpinmu adalah pemberontak dan bersekongkol dengan pencuri. Semuanya suka menerima suap dan mengejar sogok. Mereka tidak membela hak anak-anak yatim, dan perkara janda-janda tidak sampai kepada mereka. Hal ini mengungkapkan bahwa ambisi para pimpinan demi uang suap bersedia bekerja sama dengan pencuri dan memberontak terhadap atasannya dan korban penindasannya adalah rakyat kaum lemah, anak yatim dan para janda. Perkara mereka "disimpan" atau ditutup, dianggap sepi, dan pura-pura tidak tahu. Sikap aparat yang demikian masih terjadi sampai sekarang. Dalam I Samuel 8:3 dikisahkan mengenai masalah suap :"Tetapi anak-anaknya itu tidak hidup seperti ayahnya, mereka mengejar laba, menerima suap dan memutarbalikkan keadilan." Samuel yang sudah tua ingin mewariskan jabatannya kepada anaknya, tetapi anaknya berperilaku buruk, suka menerima suap dan memutarbalikkan keadilan sehingga tidak disukai oleh orang-orang Israel. Karena itu ia ditolak oleh masyarakat Israel untuk menduduki jabatan ayahnya. Seorang ayah yang baik, tetapi karena tidak bisa mendidik anaknya dengan baik, maka ia menjadi orang pelaku penerima suap dalam tugasnya.

Menurut Verkuyl, bahwa orang yang memberi suap adalah pembujuk atau membawa seseorang kepada suatu "cobaan" untuk berbuat ketidak-adilan. Dengan kata lain, pemberi suap adalah orang yang berperan sebagai pembujuk, berarti keputusan terjadinya kasus suap bukan di tangan pemberi suap tapi penerima suap. Karena jika si penerima suap "tidak setuju" maka tidak terjadi kasus suap. Tegasnya, penerima suap menjadi faktor "penentu" terjadinya kasus suap. Pemberi suap memang tidak dikecam Allah, tidak berarti ia tidak bersalah. Pemberi suap bersalah karena memberi batu sandungan. Paulus mengatakan, "Jangan kita membuat saudara kita jatuh atau tersandung" (Roma 14:13). Pemberi suap juga bersalah karena 
melakukan kompromi dengan dosa. Kedua kesalahan tersebut akan dibahas tersendiri pada bagian selanjutnya di bawah ini.

Orang yang melakukan pemberian suap, dilakukan dengan membujuk aparat birokrat agar mau menerima ajakan dalam kasus suap, adalah memberi batu sandungan kepada aparat agar terjatuh dalam dosa suap, yang semula selalu jujur tapi karena bujukan imbalannya sangat menarik, akhirnya bersedia mengikuti kemauan sang pembujuk, dan jatuhlah ia dalam dosa. "Mereka tersandung padanya, karena mereka tidak taat kepada firman Allah" (I.Petrus 2:8). Kepada pembujuk, "Jangan menjadi batu sandungan bagi mereka yang lemah" (I.Kor.8:9. Dan Imamat 19:14, "Janganlah kautaruh batu sandungan, tetapi engkau harus takut akan Allahmu, Akulah Tuhan."

Pada waktu Tuhan Yesus menyembuhkan orang sakit pada hari Sabat, maka orang-orang Farisi bersekongkol dengan orang-orang Herodian untuk membunuh Yesus (Markus 3:6). Bersekongkol atau bekerja sama untuk melakukan pembunuhan. Meskipun pemberi suap hanya bersalah sebagai pembujuk, dan ia sudah mengerti bahwa berbuat suap itu adalah dosa, namun demi kepentingannya ia melakukan kompromi dengan dosa agar tujuannya tercapai. Berarti pemberi suap adalah melakukan perbuatan dosa juga, karena dosa suap tak akan terjadi kalau tidak ada pemberi suap.

\section{Pandangan Alkitab Tentang Pungli}

Pengertian pungli adalah menyangkut pemerasan atau permintaan memaksa dalam jabatan. Yang dibicarakan dalam Firman Tuhan mengenai pungli adalah yang berkaitan dengan pemerasan yang dilakukan oleh orang yang memiliki kekuasaan, yaitu dalam kitab Amos 4:1: "Dengarlah firman ini, hai lembu-lembu Basan, yang ada di gunung Samaria, yang memeras orang lemah, yang menginjak orang miskin..." Amos menyapa wanita wanita itu dengan sebutan lembu-lembu Basan yang ada di gunung Samaria adalah perkataan yang kasar, sebab mereka ini yang membuat para suaminya melayani dirinya, dan menjadi pendorong untuk melakukan korupsi atau pemerasan dan pungutan tidak resmi serta perbuatan buruk lainnya, agar mereka itu dapat hidup berfoyafoya. Sehingga di zaman Amos ini mereka disebut pula kaum perempuan yang memeras orang lemah, dan yang menginjak orang miskin. Kitab Pengkhotbah 7:7 menjelaskan masalah pemerasan, sebagai berikut: "Sungguh, pemerasan membodohkan orang berhikmat, dan uang suap merusakan hati." Yang dipersoalkan dengan pemerasan dalam ayat itu bukan korbannya, tapi pelaku pemerasannya. Bila orang berhikmat tergoda melakukan pemerasan untuk memperkaya diri, maka ia menjadi bodoh dan hatinya menjadi rusak. Demikian juga untuk penerima suap. Sering orang berpendapat bahwa pemerasan yang dilakukan oleh para pejabat adalah gejala zaman sekarang, padahal itu sudah menjadi kenyataan sejak zaman dahulu kala.

Yohanes juga menghadapi permasalahan pemerasan, tertulis dalam kitab Lukas 3:14 "Dan perajurit-perajurit bertanya juga kepadanya:"Apakah yang harus kami perbuat?" Jawab Yohanes:"Jangan memeras dan jangan merampas dan cukupkanlah dirimu dengan gajimu." Pada waktu itu Yohanes tampil sebagai pembimbing rohani, saat ditanya oleh perajuritperajurit ia menegaskan bahwa setiap perajurit dan pemungut cukai harus bertindak dengan adil, dan mencukupkan dengan penghasilannya serta tidak tamak. Ditegur pula pemungut cukai yang membayar sejumlah uang (menyogok) kepada pejabat Roma, guna memperoleh hak istimewa dalam memungut pajak dan suka memeras.

Masalah pemerasan nampak pula dalam kitab Ulangan 24:14sebagai berikut: "Janganlah engkau memeras pekerja harian yang miskin dan menderita, baik ia saudaramu maupun orang asing yang ada di negerimu, di dalam tempatmu." Hal itu menegaskan agar para tuan atau majikan tidak memeras kaum pekerjanya, tidak mengurangi hak upahnya dengan alasan pungutan apapun, baik terhadap sanak saudara maupun orang asing.

Imamat 19:3, Ulangan 24:14, Amos 4:1, Yeremia 22:17, Yeheskiel 22:12, Pengkhotbah 7:7, Mazmur 119:134, Lukas 3:14, berbicara mengenai pemerasan atau perbuatan pungli. Allah tidak menghendaki perbuatan memungut 
atau menerima pungli, yang disebutnya sebagai pemeras sesama manusia yang membuat penderitaan dan sengsara orang lain. Dan Tuhan menegor dan mengecam keras pelaku pemerasan atau penerima pungli. Bahkan Mazmur 72:4 mengatakan, akan "meremukkan pemeras-pemeras."

Pemberi pungli adalah orang lemah korban pemerasan, yang dilakukan oleh orang yang memiliki kekuasaan, yaitu oknum aparat birokrasi pemerintah. Mereka adalah orang yang tertindas tak berdaya untuk menentangnya, suatu keterpaksaan mengingat adanya ancaman kesulitan kalau tidak dipenuhi permintaan pungli. Firman Tuhan sering mengatakan kepeduliannya kepada orang yang tertindas. Allah ingat kepada orang yang tertindas (Mazmur 9:13).

Allah melarang adanya pemerasan kepada sesama manusia (Im.19:13). Allah tidak menyukai dan mengecam orang yang memeras orang lain (Mazmur 105:14; Yeheskiel 22:7,12; Lukas 3:14; I Tawarikh 16:21; Amos 3:9,10). Allah mengecam mereka yang memeras orang miskin (Amos 4:1). "Kiranya ia memberi keadilan kepada orang-orang yang tertindas dari bangsa itu, menolong orang-orang miskin, tetapi meremukkan pemeras-pemeras!"(Mazmur 72:4). Allah memperingatkan, "Aku akan bertindak terhadap segala penindasmu" (Zefanya 3:19). Maka relevansinya dapat dikatakan, bahwa Allah juga mengecam para pemungut pungli atau penerima uang pelicin.

\section{KESIMPULAN}

Menurut pandangan Alkitan pada kasus suap, Allah mengecam keras kepada penerimanya tapi tidak mengecam pemberinya. Pemberi suap yang beperan sebagai pembujuk tersebut berdosa karena berkompromi dengan perbuatan dosa, dan memberi batu sandungan, serta memutarbalikkan keadilan. Allah juga mengecam keras kepada penerima pungli, Allah akan meremukkan pemeras-pemeras tersebut. Kepada pemberi pungli, Allah justru menaruh belas kasihan karena mereka sebagai korban penindasan.

\section{REKOMENDASI}

Sikap selektivisme yaitu umat Kristen dalam menghadapi praktek uang pelicin, mesti mempelajari lebih dulu apakah termasuk bentuk suap atau pungli. Jika bentuk suap harus dihindari dan jangan dilakukan karena itu berdosa, yaitu ada pelanggaran prosedur, dan inisiatif datang dari dirinya.

\section{DAFTAR PUSTAKA}

Dharmawan dan Al Soni BL de Rosari, peny. Surga Para Koruptor, Jakarta: Kompas Media Nusantara, 2010.

Strong, James. The New Strong's: Exhaustive Concordance of The Bible. New York: Thomas Nelson Publisher, 1984

Soedjono, Pungli. Bandung: Sinar Baru, 1983.

Verkuyl, Etika Kristen bagian Sosial Ekonomi. Jakarta: BPK Gunung Mulia, 1982.

Soedarmo, R. Ikhtisar Dogmatika Jakarta: BPK Gunung Mulia, 1982.

Budiman, Tafsiran Alkitab Surat-Surat Pastoral I,II Timotius dan Titus. Jakarta: BPK Gunung Mulia, 1984.

Brill, Weley. Tafsiran Surat Ibrani. Bandung: Kalam Hidup, 1981.

Cairns, J. Tafsiran Alkitab Ulangan 2. Jakarta: BPK Gunung Mulia, 1986.

Widyapranawa, S.H. Tafsiran Alkitab Yesaya 112, Jakarta: BPK Gunung Mulia, 1985.

Boland, B.J. Tafsiran Alkitab Kitab Amos. Jakarta: BPK Gunung Mulia, 2005.

Lembaga Biblika Indonesia, Injil Lukas Yogyakarta: Kanisius, 1989.

Pilon, Tafsiran Alkitab Mikha Jakarta: BPK Gunung Mulia, 1983.

Kamus Besar Bahasa Indonesia, Jakarta: Balai Pustaka, 2000. 